\title{
Testimonio, subjetividad y lenguajes femeninos en contextos de violencia política en América Latina
}

\author{
Feminine Languages and Subjectivation Annotations on Political \\ Violence and Testimonial Narrative
}

\section{Martha CECILIA HERRERA}

Universidad Pedagógica Nacional · malaquita10@gmail.com

Docente investigadora de la Universidad Pedagógica Nacional. Magíster en Historia de la Universidad Nacional de Colombia (Colombia) y Doctora en Filosofía e Historia de la Educación de la Universidad Estadual de Campinas (Brasil). Fundadora del grupo de investigación Educación y Cultura Política.

\section{Carol Pertuz Bedoya}

Universidad Pedagógica Nacional·carolpertuz@hotmail.com

Licenciada en Psicología y Pedagogía de la Universidad Pedagógica Nacional (Colombia). Tecnóloga en Sistematización de Datos de la Universidad Distrital Francisco José de Caldas. Miembro del grupo de investigación Educación y Cultura Política.

RECIBIDO: 23 DE ENERO DE 2015

ACEPTADO: 3 DE JUNIO DE 2015

Resumen: En el marco del proyecto de investigación Narrativa Testimonial, Políticas de la Memoria y Subjetividad en América Latina, el presente artículo lleva a cabo algunas reflexiones sobre un corpus documental basado en textos escritos por mujeres que hicieron parte de grupos de izquierda que optaron por la vía armada entre los años 60 y 90 del siglo pasado. Con ello se busca iluminar los modos como la violencia política y el terrorismo de estado modularon la cultura política en América Latina e incidieron en la configuración de las subjetividades de quienes fueron actores directos o indirectos de dichos acontecimientos, al tiempo que se explora en dichas narrativas algunas de sus implicaciones sobre el tiempo presente.

Palabras clave: Violencia política, subjetividades políticas, narrativa testimonial.
Abstract: In the framework of the research project Testimonial Narrative, Policies of Memory and Subjectivity in Latin America, this paper reflects on a documentary corpus based on texts written by women who once belonged to leftist groups opting for the arms between the 60 's and the 70 's in the 1900 's. Through this, we aim at enlightening the ways in which political violence and State terrorism modulated political culture in Latin America and affected the configuration of the subjectivities of direct or indirect actors in these events. At the same time, the paper explores some of the implications for the present time in these narratives.

Key words: Political violence, political subjectivities, testimonial narratives 
Ayer lo defendimos con banderas, poemas y fusiles y hoy lo seguimos haciendo con campanas sonando al porvenir, al viento como los cantos de palomas con angustias de paz, haciendo del Internet una nueva arma de futuro y de nuestro cansancio un silencio aborrecido. Con rencor a la muerte prematura, sin consuelo por la muerte de inocentes. Sin perdonar, sin olvidar. Porque amamos la vida. Tuvimos derecho al fusil, como tuvimos derecho al goce libre de nuestro propio cuerpo. Y si nada de todo eso nos fue dado, sino que debimos arrebatarlo, pagamos muy alto el precio de perderlo todo. Y con el descuartizamiento de nuestra psiquis y el dolor extremo del cuerpo.

Zabaleta

\section{Introducción}

Las décadas de los 60 y 70 del siglo XX constituyeron en América Latina el despertar de una serie de movimientos sociales acompañados del surgimiento de organizaciones políticas y, dentro de ellas, de grupos que optaron por la vía armada, a la luz de una serie de expectativas movidas por la revolución cubana, por diversos movimientos de liberación nacional y por la crisis, en general, de la institucionalidad del orden social legitimado en la región. Así mismo estas décadas se caracterizaron por la eclosión de movimientos culturales en cuyo contexto se cuestionó el papel de la mujer y los roles tradicionales entre los sexos, al tiempo que emergieron los jóvenes como categoría específica debido a su protagonismo, representando, junto con las mujeres, el paradigma de algunos de los cambios dados en el período.

Igualmente en buena parte de los países la densificación de las poblaciones urbanas estuvo acompañada de transformaciones en el campo de la comunicación así como de procesos de modernización lo cual incidió en la ampliación de las tazas de alfabetización, en mayores posibilidades de intercambio y de nuevos espacios de socialidad y, en general, en la circulación de modelos y estilos de vida que desbordaron las fronteras locales y nacionales, cuestionando, en su conjunto, los imaginarios sociales e individuales de los estados nación y, en términos amplios, del proyecto moderno que había acompañado el avance del capitalismo.

El ambiente político y cultural del período estuvo marcado por la crisis de los modelos de desarrollo en el continente y la deslegitimación de buena parte de los proyectos políticos de las clases dominantes que los representaban, lo cual condujo en algunos de los países al terrorismo de Estado, como fue el caso del Cono Sur, y a regímenes de democracia restringida en otros de los países del continente, en la procura de obtener control social, político e ideológico, poner bajo cintura a los movimientos sociales y a los grupos políticos de oposición, generando condiciones para las 
modificaciones estructurales llevadas a cabo bajo directrices norteamericanas, en el contexto de la Guerra Fría.

A lo largo de estas décadas los sujetos fueron modulados, en muchos de sus aspectos, por procesos de subjetivación en los que la violencia política dejó una profunda huella en sus subjetividades, lo cual tuvo desdoblamientos diferenciales para el conjunto de la sociedad, de acuerdo a los modos como ésta incidió en sus experiencias y en el transcurrir de sus vidas cotidianas. En este sentido, el estudio en torno a la configuración de subjetividades y de constitución de sujetos políticos en el período deberá dar cuenta de un panorama que aunque heterogéneo y desigual, sí lleva la impronta de los mismos acontecimientos históricos en los que la violencia política tuvo un despliegue significativo.

Desde este horizonte, en el presente trabajo se busca dilucidar las maneras como se configuraron las subjetividades de mujeres que pertenecieron a organizaciones políticas de izquierda, centrándonos en militantes de grupos político-militares, a través de las narrativas testimoniales en las que plasmaron sus vivencias y percepciones sobre la violencia política entre 1960 y 1990. El artículo se aproxima, en primer lugar, a algunas reflexiones en torno al contexto de violencia política que caracterizó las décadas comprendidas entre 1960 y 1990. En segundo lugar, se hacen algunas disquisiciones en torno al testimonio y su institucionalización como género en los años 60 y 70, para pasar a abordar, a continuación, alguna de las producciones narrativas elaboradas por tres mujeres: en Chile (Carmen Castillo), Argentina (Pilar Calveiro) y Colombia (Vera Grabe).

\section{Violencia y política: una relación inacabada}

Las relaciones entre política y violencia son bastante complejas y sus delimitaciones han estado sujetas a diferentes acercamientos en distintos períodos históricos, lo cual ha llevado en unas ocasiones a resaltar sus proximidades y en otras a relievar el extrañamiento entre estos dos términos. A partir de la segunda mitad del siglo XX este debate cobra vigencia para tratar de comprender las dinámicas políticas que caracterizaron estas décadas y las actuaciones de los distintos grupos que tuvieron expresión en el campo político en el plano mundial y en, especial, en el continente latinoamericano, incidiendo en la configuración de las subjetividades. 
M. Cecilia Herrera, C. Perduz Bedoya. Testimonio, subjetividad...

\section{Violencia fundadora y violencia política}

Los seres humanos han hecho uso de diferentes estrategias para solucionar los conflictos implicados en la convivencia y en la configuración de los órdenes sociales, para lo cual han acudido en muchas de las ocasiones al uso de la violencia. Este hecho ha generado discusiones sobre la legitimidad o no de la misma, de acuerdo a quien la detente, dando pie a diversas formas de resolución.

En primer lugar podemos decir que el orden de lo sagrado ha sido una de las soluciones más antiguas de esta legitimación, tal vez la primera en términos históricos como lo indica René Girard (1982), para quien Hieros, que procede del védico isirah (fuerza vital), implica tanto una violencia-fuerza destructora como una violencia-orden constructora. Así, existe un lazo entre los dos tipos de violencia (la que divide y la que une) que vinculan a la sociedad humana y a la religión o, mejor, a lo sagrado, con esta noción en un todo comprensivo en el cual se modulan, no sin dificultades, las dos acepciones de la violencia.

En segundo lugar, a la par con la dimensión de lo sagrado, la historia ha evidenciado otras salidas como la de las normas jurídicas, en cuanto forma de control de las fuerzas violentas, haciendo uso para ello del ejercicio de la racionalidad; fórmula que cobra importancia con la configuración de los Estados y de manera particular con los Estados modernos, contexto en el que surgen interrogantes sobre el uso legítimo que éstos tienen para ejercer la violencia (su monopolio) y, en este orden de ideas, de la descalificación de otras fuerzas que hagan uso de la misma por fuera de la acción estatal. Al respecto, en los distintos acercamientos persiste como nudo problemático bajo qué parámetros un Estado adquiere legitimidad entre sus gobernados para hacer uso de la violencia y así mismo cuáles son los límites de dicho ejercicio, en torno a lo cual los teóricos se dividen entre quienes la justifican y quienes la descalifican como modalidad para acceder o mantener el poder; de este modo, mientras unos enfatizan en el problema de la dominación otros lo hacen en el del consenso.

Ricoeur (1998) propone una teoría del Estado en la que articula estas dos aproximaciones, afirmando que el Estado debe actuar desde una idea del poder en términos de concertación pero valiéndose, al mismo tiempo, de un uso moderado de la violencia para obtener su legitimación. Ricoeur asevera (2009) que la violencia ha estado siempre en juego en cuanto recurso del Estado para garantizar la supervivencia de las comunidades, de las cuales ha sido mediador y continúa siéndolo en la actualidad. A la vez define la violencia como un componente fundante de toda comunidad, lo cual le lleva a afirmar que si bien la violencia es una constante entre los seres humanos y, por lo tanto, debe ser regulada por el Estado, no es la violencia la que define al estado sino el objetivo de consolidar y proteger las comunidades (p. 100). 
Es en torno a esta finalidad suprema, la voluntad de supervivencia, que se han pronunciado las distintas escuelas de la filosofía política sobre el Estado para privilegiar en su análisis ya sea, el problema de la fuerza con la que debe operar el Estado como garante de la supervivencia de la comunidad, lo cual lleva a prestar mayor interés a asuntos referidos al poder; o ya sea, el problema de la forma como se debe llevar a cabo este propósito, lo cual conduce a preocupaciones referidas más al estado de derecho y a sus normas constitucionales (Ibid., 2009, p. 101). No obstante, la otra dimensión del Estado referida a la fuerza, también corresponde a un Estado de derecho ya que éste "no puede definirse si no se incorpora a su función el monopolio de la fuerza legítima". Por ello, "la paradoja política consiste precisamente en esta confrontación entre la forma y la fuerza en la definición de Estado" (Ibid, p. 102), en cuyo interior acecha permanentemente la huella de la violencia arbitraria y las posibilidades de su activación.

\section{Violencia política en América Latina: 1960-1990}

A la luz de las discusiones en torno al carácter legítimo o ilegítimo de la violencia para obtener el control social, para detentar el poder, se requiere situar las acciones políticas de oposición llevadas a cabo por las generaciones que vivieron en América Latina entre las décadas de los 60 y 90, así como la respuesta estatal a las mismas y el tipo de subjetividades que de allí emergieron en un contexto marcado por la represión política y el uso de la violencia.

Las expresiones de violencia política hicieron parte del entorno social y cultural en el que miembros de esas generaciones crecieron e hicieron sus primeros escarceos en la esfera de lo político a través de la militancia revolucionaria, con el fin de transformar las circunstancias históricas que les rodeaban, caracterizadas por la desigualdad social y la intolerancia política, contexto en el cual, a pesar de las preocupaciones de Arendt (1970, edición 2005), el uso de la violencia era moneda corriente.

El contexto de efervescencia social y política que caracterizó el continente latinoamericano y los idearios que fenómenos como la revolución cubana y los movimientos de liberación nacional vietnamita y argelino habían avizorado, respecto a las posibilidades de construir modelos diferentes al capitalista, condujo a la conformación de organizaciones de izquierda que tomaron las armas bajo la convicción de que los órdenes sociales existentes, y los regímenes que los representaban, habían perdido su legitimidad, diagnóstico que validaba el uso de la violencia para tomar el poder e instaurar regímenes que posibilitasen órdenes sociales más justos. Es en este marco que surgen en Chile organizaciones como el MIR, MAPU, Brigada Ramona Parra y Brigadas del Pueblo Revolucionario; en Argentina las FAR, las FAP, Montoneros y ERP; en Colombia las FARC, el EPL, el ELN y el M-19, entre otras organizaciones. 
M. Cecilia Herrera, C. Perduz Bedoya. Testimonio, subjetividad...

A pesar del optimismo que norteó estas iniciativas la mayoría de las organizaciones fueron quebradas durante los 60 y 70 por la violencia estatal, diezmando las filas de sus militantes y conduciendo a dictaduras en el Cono Sur, o al endurecimiento de regímenes considerados como democracias en otros de los países del continente (haciendo uso del estado de sitio), con base en los lineamientos de las políticas de seguridad nacional estadounidense, según los cuales los opositores al régimen fueron considerados como el enemigo a derrotar/exterminar de la misma manera a como se hacía con un enemigo externo.

Las décadas del 80 y 90 significaron en algunos de estos países procesos de transición a la democracia, a través de los cuales se quiso tomar distancia de estos años de plomo (como se los menciona para el caso argentino), pero cuyas consecuencias sobre el presente de los regímenes democráticos pende como una espada de Damocles ya que muchos de los cambios que se dieron en el plano macroestructural durante las décadas anteriores constituyen el fundamento de las actuales sociedades latinoamericanas. Por su parte Colombia aunque intentó procesos de negociación y reinserción de algunos de los grupos de izquierda alzados en armas, continuó con un proceso de violencia política en el cual el paramilitarismo y el narcotráfico van a redefinir algunas de las características del período anterior, dando continuidad a un complejo conflicto armado en el que el desplazamiento interno ha situado al país en los primeros lugares a nivel mundial.

El restablecimiento de la democracia y el reordenamiento de los valores sociales en función de la transición produjo modificaciones en la mirada en torno al uso de la violencia bien sea en términos de la preservación o del acceso al poder. Así, una mirada pasada por el filtro de los saldos de dos guerras mundiales y los efectos de la mal llamada Guerra Fría, cuyas políticas alcanzaron a tocar el corazón de las sociedades latinoamericanas, ha llevado a cuestionar la legitimidad de la violencia en un contexto en el cual se han afianzado los derechos humanos y la defensa de proyectos y regímenes políticos de carácter democrático. Como consecuencia de ello el tema de la violencia política, más allá de su rechazo, parece quedar por fuera de los debates en la agenda pública en pro de políticas de reconciliación en las que no se ha alcanzado, por un lado, a saldar cuentas con el pasado (violento) que estas sociedades han heredado y, por otro lado, en las cuales se escamotea el hecho de que en la esfera política el componente de la violencia hace parte de las tensiones con las que toda sociedad debe lidiar.

De este modo, con base en la actitud de invalidar el uso de la violencia política per se, se hace común la emisión de juicios descontextualizados con aseveraciones que condenan la recurrencia a los medios violentos como posibilidad de acceso al poder y alternativa de subversión de los órdenes sociales vigentes. Esta manera de tramitar los acontecimientos de violencia política dados en el continente latinoamericano en el pasado reciente caló en la memoria social incidiendo en los posicionamientos 
M. Cecilia Herrera, C. Perduz Bedoya. Testimonio, subjetividad...

respecto a los mismos. Según Calveiro: "Se podría decir que esta violencia de "escarmiento" del Estado, contra aquellos que intentaban poner en entredicho su núcleo más medular, permanece como memoria del miedo gigante que no se atreve siquiera, en el presente, a reconsiderar la difícil y decisiva relación entre política y violencia” (Calveiro, 2005, p. 190).

Desde este horizonte problemático toma relevancia el acercamiento a las miradas de los diferentes actores que jugaron algún papel en los acontecimientos políticos acaecidos entre 1960 y 1990, con miras a rastrear las concepciones acerca de la violencia política y los procesos de subjetivación que se constituyeron en referentes de las generaciones vinculadas a lo político en este período.

\section{Testimonio, Subjetividad y lenguajes femeninos}

Entre las décadas del 60 y el 90, el campo cultural y el político encontraron en América Latina importantes puntos de confluencia. Podría decirse que todo lo cercano al campo cultural se convirtió durante los regímenes dictatoriales del Cono Sur y las democracias restringidas del resto del continente en foco de hostigamiento y, al mismo tiempo, en la esfera de combate desde la cual los perseguidos políticos llevaron a cabo su acción política de resistencia; situaciones que derivaron en que la actividad política fuera definiéndose cada vez más como una política cultural (Yúdice, 2003, p. 128).

Dentro de las expresiones culturales privilegiadas durante este periodo, se sitúa el testimonio como blasón predominante de tal política cultural. Este género había tomado fuerza en el continente desde finales de la década de los 60, de la mano del auge de los movimientos sociales que se expresaban al margen de los partidos tradicionales y al cual se le dio legitimidad en el campo de la literatura cuando fue incluido en el Premio Casa de las Américas (Ochando 1977). Además de su evidente cercanía con métodos de acción política de oposición, característicos de la época -inscritos en el paradigma de denuncia como posibilidad de dar a conocer al mundo condiciones específicas de represión, o en el jurídico como prueba del testigo ante los tribunales internacionales- los testimonios lograron crear rupturas importantes en las "dicotomías constitutivas de la modernidad hegemónica” (Yúdice, 2003, p. 128); así, por ejemplo, traspasaron y tornaron indiferenciables la esfera pública y la privada puesto que en el propósito de la denuncia llevaron a lo público aquello que se pretendía privado.

De esta manera, esta matriz discursiva se consolidó como posibilidad de la práctica democrática en los lugares en que había sido frustrada la realización del cambio social deseado; con la palabra como arma y la literatura como trinchera la izquierda revolucionaria del continente intentó mantener en firme los valores que las dictaduras destruían a su paso. Así, "mientras los activistas políticos integraban la producción testimonial en el paradigma de las nuevas luchas, el campo cultural trataba de inscribirla en 
M. Cecilia Herrera, C. Perduz Bedoya. Testimonio, subjetividad...

las nuevas formas de lo literario" (Peris, 2008, p. 124). Para comprender la significación histórica del testimonio en América Latina es necesario en palabras de García (2013):

considerar un dispositivo metadiscursivo programáticamente impulsado desde el final de los años

'60, que interrelaciona dos operaciones simultáneas: convierte en literatura una serie textual que, hasta el momento, se entendía como extraliteraria -periodística, científica, política-, y la representa como "propiamente latinoamericana”, en la medida en que aludía a la agitada vida política de la región -como insignia básica de la autopercepción de la época- (p. 370).

Desde este horizonte de comprensión, pasaremos a hacer una aproximación de algunas narrativas elaboradas por mujeres en Argentina, Chile y Colombia, en las que se trata de abarcar diferentes circunstancias, formas de construir los relatos y de asumir la continuidad del trabajo político, a partir de la reelaboración de las propias vivencias en torno a la violencia política. Para ello, aunque dialoguemos con una pluralidad de voces, nos centraremos en tres mujeres: Carmen Castillo, chilena, militante del MIR; Pilar Calveiro, argentina, militante de Montoneros; y Vera Grabe, colombiana, militante del M-19.

\section{El proyecto político de la izquierda chilena y la voz del testigo}

Chile significó como país una apuesta diferente a la de Cuba, en el sentido en que a través del movimiento de la Unidad Popular, configurado por diferentes grupos de oposición de izquierda y de sectores democráticos, Salvador Allende llegó a la presidencia en 1970 legitimándose un proyecto que buscaba cambios en la estructura económica y social bajo los idearios del socialismo (una vía chilena al socialismo con empanadas y vino tinto). Allende sería el primer político de orientación marxista que llegaba al poder, a través de elecciones generales en un Estado de Derecho, en el marco de una sociedad occidental. En dicho contexto el MIR (Movimiento de Izquierda Revolucionario) creado en 1965 como grupo armado con orientación marxista, que se encontraba en la clandestinidad, salió a la luz pública y comenzó a llevar a cabo iniciativas de apoyo al régimen de Allende, aunque guardando una prudente distancia del mismo.

No obstante, en este período la sociedad chilena se hallaba dividida y los problemas sociales y la violencia política empezaron a copar buena parte de los espacios, conduciendo a problemas de gobernabilidad y al fortalecimiento de las fuerzas de extrema derecha. Esta situación condujo finalmente al golpe militar, dado el 11 de septiembre de 1973, al bombardeo de la Casa de la Moneda y a la muerte de Salvador Allende, dando comienzo a una sangrienta dictadura a través de una Junta Militar bajo el mando de Augusto Pinochet que se prolongaría hasta 1989, año en el que se inicia un proceso de transición en el cual los acuerdos con los militares van a marcar un camino tortuoso para la instauración 
M. Cecilia Herrera, C. Perduz Bedoya. Testimonio, subjetividad...

de un régimen democrático que debía saldar cuentas con el pasado dictatorial pero que, al mismo tiempo, daba continuidad a las políticas económicas y sociales puestas en marcha en el período. No hay que olvidar que Chile significó el laboratorio de las políticas neoliberales implantadas en el continente, y que encuentra en los Chicago Boys el grupo de tecnócratas chilenos encargados de su puesta en acción durante el período de la dictadura, el cual se formó en la Universidad de Chicago bajo la égida del economista Milton Friedman.

Los acontecimientos chilenos significaron la derrota de muchos de los sueños que la izquierda latinoamericana venía acariciando y, si esto había pasado con un proyecto político apoyado por la institucionalidad del estado de derecho, ya se podía avizorar lo que vendría para las organizaciones de izquierda, tanto al interior de Chile como de los demás países de América Latina, respecto a las posibilidades de inserción de sus proyectos en el marco de las instituciones vigentes, lo cual valga la pena aclarar, tampoco era una aspiración en dicho momento histórico, pues, como ya se ha mencionado, la opción era la toma revolucionaria del poder y la instauración de un orden social diferente al capitalista, bajo el entendido de que "la burguesía” no entregaría el poder, a través de medios pacíficos.

En este horizonte buena parte de la intelectualidad de izquierda y progresista chilena salió al exilio o se clandestinizó en el mismo Chile, en ocasiones por su propia voluntad y, en muchos de los casos, por la persecución política. Dentro de este contexto los escritores chilenos en el exilio catapultaron con sus actuaciones la denuncia del régimen de Pinochet y la defensa del proyecto político de la Unidad Popular, posibilitando una serie de transformaciones con incidencias en el campo político y en el cultural en toda América Latina. Para Jaume Peris:

la figura del 'escritor exiliado' fue, de hecho, uno de los puntos de anclaje en torno a los que se llevaría a cabo ese proceso de redefinición del sistema literario latinoamericano. En el caso chileno ello adquiriría una especial intensidad. Por una parte, porque el carácter enormemente simbólico que el caso de Chile había adquirido en el imaginario de la izquierda mundial convirtió a los chilenos exiliados en los portadores emblemáticos de los proyectos de transformación social que la Junta Militar había cercenado. Por otra parte, porque los propios escritores tematizaron insistentemente su condición de exiliados, convirtiéndola en el nudo identificatorio que los marcaba como sujetos de la derrota histórica de un proyecto que sólo sobrevivía en ellos y, a la vez, como sujetos a los que la violencia política había arrebatado todo su mundo afectivo (Peris, Op. Cü., p. 127).

Es en el marco de este horizonte que Carmen Castillo (hija del político y arquitecto Fernando Castillo Velasco y de la escritora Mónica Echeverría, así como profesora de historia e investigadora en el 
M. Cecilia Herrera, C. Perduz Bedoya. Testimonio, subjetividad...

Centro de Investigaciones de Historia de América Latina de la Universidad Católica en el período) lleva a cabo una producción de carácter testimonial, algunos de cuyos elementos expondremos a continuación.

\section{Ese día de octubre en Santiago: la memoria herida de Carmen}

Esa casa incrustada en mí desde ese sábado 5 de octubre de 1974. Sí, todo empezó en esa casa, el rompimiento con mi país, el desgarramiento de una familia, las andanzas (Calle Santa Fe, 3:15).

Los lugares de la memoria se prenden en la piel, se incrustan en el cuerpo, para señalar con ello anclajes del recuerdo alrededor de los cuales se condensan la memoria y el olvido; su sola evocación puede dar cuenta del momento en el que la identidad del sujeto quedó resquebrajada y a donde éste debe volver, una y otra vez, en los movimientos de su reconfiguración para elaborar el duelo de la memoria herida, de las pérdidas, para ser otro ser. Esta es la apuesta que Carmen Castillo le hace a su narrativa sobre la dictadura chilena al atar a la casa de la calle Santa Fe buena parte de los recuerdos sobre su militancia y su relación con Miguel Enríquez (secretario general del MIR y una de sus figuras más importantes en la clandestinidad). En esta casa, después de un enfrentamiento con miembros de la DINA (Dirección de Inteligencia Nacional), Miguel es asesinado y Carmen es herida de gravedad, siendo detenida y llevada a un hospital militar para ser obligada posteriormente a abandonar el país bajo amenaza de muerte.

Cuatro son las producciones que podemos mencionar sobre el despliegue de Carmen en torno a su subjetividad y a las memorias de violencia política evocadas a partir de los hechos de la Calle Santa Fe: El libro Un día de Octubre en Santiago, los documentales La Flaca y Calle Santa Fe. Y, en otro registro, el libro escrito a cuatro manos con su madre Mónica Echeverría, Santiago - Paris: El Vuelo de la Memoria. Son los mismos elementos los que golpean la memoria de Castillo y activan la búsqueda de sus recuerdos: el hecho puntual del 5 de octubre y su significado emblemático, sus pérdidas personales, su condición femenina, su compromiso social y militante, la precariedad de los recuerdos, el siempre inconcluso balance que bordea entre la melancolía y la esperanza que vuelca en la acción política en defensa de los derechos humanos y la reivindicación de los proyectos políticos setentistas, de los cuales, aunque reconoce sus errores, nunca invalida sus apuestas ni la pasión que les fue característica.

Su primer trabajo Un día de Octubre en Santiago, escrito en 1979, fue publicado en francés en 1980, luego en español en México en 1982 y, 20 años después, en Chile (1999). El libro está compuesto por tres capítulos y su estructura se apoya, a nuestro modo de ver, en la idea de los lugares de la memoria. El primero, La casa azul celeste de Santa Fe, inicia con el nudo central que cambió 
M. Cecilia Herrera, C. Perduz Bedoya. Testimonio, subjetividad...

definitivamente el curso de su vida: el enfrentamiento armado que termina con la muerte de Miguel y ocasiona su propio exilio, evocando, al mismo tiempo, los días anteriores al Golpe Militar. El segundo, La casa José Domingo Cañas, sitúa a la autora en el exilio y sus intentos por reconstruir y comprender el asalto a la casa de la calle Santa Fe, introduciendo relatos sobre torturas hechas por la DINA (Dirección de Inteligencia Nacional) a algunos militantes del MIR en ese centro clandestino, el cual será convertido durante la democracia, en 2002, en un sitio memorialístico y en 2010 instituida como casa de la memoria. El tercero, La calle Claude-Bernard, se detiene un poco más en el transcurrir de Carmen en el exilio y sus búsquedas por desentrañar los hechos que desencadenaron la muerte de Miguel y su propio exilio, así como los responsables del desastre. Una pregunta pende en el aire sobre sus amigos y compañeros de militancia: “QQué hicieron el 5 de octubre?”. Ella desea “reconstituir el trayecto que condujo al enemigo hasta la casa de Santa Fe"(p. 43). Allí habla de las pérdidas, de los muertos, de los desaparecidos, pero deja claro que no todo acabó aquel día de octubre puesto que el compromiso y la lucha revolucionaria continúan.

En 1993 realiza el documental La Flaca Alejandra: vida y muertes de una mujer chilena, en donde trata de desentrañar la subjetividad y los sentimientos de Marcia Merino, una militante del MIR al servicio de la DINA, cuyas declaraciones desencadenaron el hallazgo del sitio en el que Miguel y Carmen se encontraban. Marcia Merino, además, fue utilizada para reconocer a varios integrantes del MIR, posteriormente torturados y asesinados. Este documental ganó el FIPA de Oro en el Festival Internacional de Programas Audiovisuales de Biarriz en 1994, el Nestor Almendros Award en 1995 y otra serie de galardones en Ginebra, Montecarlo, San Francisco y Nueva York. Castillo comenta en una entrevista en 1999 como la escritura le empezó a quedar corta para hablar de estos hechos, motivo por el cual decidió hacer uso del formato documental (Bedregal, 1999, s.p.).

Los 59 minutos de duración de este documental constituyen una larga conversación entre Carmen Castillo y Marcia Merino recreada con la visita al centro clandestino de tortura José Domingo Cañas donde ésta estuvo recluida. Carmen Castillo vuelve a Chile en 1992, para rodar este trabajo, en la época en que Marcia (liberada de la cárcel siete meses antes) se presenta en tribunales para acusar a sus viejos jefes de la DINA, en un gesto de arrepentimiento y deseo de perdón, el cual es acompañado de la publicación de una biografía, Mi verdad (1994). La salida a la luz de los libros testimoniales de Marcia Merino y el de Alejandra Arce, El Infierno (1993) (otra militante que jugó un papel similar al de Merino), acompañados del documental de Carmen Castillo, causaron desazón en la sociedad chilena; de cierta manera sus testimonios ejemplificaban, en la época de la Transición, el triunfo de la dictadura en el propósito de quebrar los idearios de la generación que se había agrupado en torno a la Unidad Popular. 
M. Cecilia Herrera, C. Perduz Bedoya. Testimonio, subjetividad...

Dice Castillo: "Marcia que era de nosotros, que era como nosotros, cómo llegó a convertirse en eso, a convertirse en qué...” (La Flaca, 4:10-4:14). Para Peris:

Haciendo un paralelo con los procesos subjetivos vividos por las colaboradoras, no era difícil constatar que la violencia, al adquirir un carácter sistemático, había jugado un rol esencial en la disolución y el derrumbe de las identidades políticas que habían hecho posible un proceso social como el que Chile había vivido antes del golpe de Estado. Pero que además, la violencia extrema de los campos había contribuido decisivamente a la creación de nuevas identidades y sujetos sociales marcados por la docilidad, perfectamente moldeables por el poder político y funcionales por tanto a la nueva sociedad que el régimen militar estaba tratando de implantar (Peris, Op. Citt., p. 30).

En 2007 con los mismos ingredientes de la Calle Santa Fe, Castillo vuelve a sumergirse a través de un documental del mismo nombre, sobre acontecimientos personales tejidos alrededor de historias colectivas, tratando de incorporar a la memoria social los movimientos de oposición, la denuncia de la dictadura y las huellas de los ausentes que pagaron con su vida las utopías de una generación de la cual ella hizo parte. Este trabajo recibió el Premio Altazor 2008 en Artes Audiovisuales.

No hay que olvidar que Castillo es historiadora y en ese sentido en sus textos habrá interés en mostrar, de manera cuidadosa, los recursos paratextuales de sus trabajos, así como la heterogeneidad y fragmentación de la memoria, al tiempo que su fragilidad. Su documental Calle Santa Fe inicia con un texto escrito en el que plasma el primero de los acontecimientos que anuda la trama: el golpe militar de Pinochet al gobierno democrático de Salvador Allende, el 13 de septiembre de 1973, y la consecuente represión que se desató en contra de toda resistencia al golpe y, de manera particular, al MIR como organización. A continuación presenta el clip de la noticia televisada sobre el 5 de octubre de 1974 en la que se reporta el asalto por parte de los militares a la casa de la calle Santa Fe, la resistencia armada por parte de Miguel Enríquez y Carmen Castillo y el posterior hallazgo del cadáver de Miguel y del cuerpo de Carmen herida de gravedad (Calle Santa Fe, 2007, 0:01-1:04).

Una vez que termina la noticia en la que se muestra la casa de la Calle Santa Fe, unas manos, las de Carmen Castillo, recorren fotografías sobre estas mismas imágenes; en su escritorio reposan periódicos del MIR, diversos libros sobre política y papeles relacionados con la militancia, fotografías (1:10-1:36), permitiéndole a ella zambullirse, con alguna legitimidad, en la Historia Oficial a través de su historia personal llena de otros relatos que pugnan por oficializarse y en los que encajan, como piezas del mismo rompecabezas, los sentimientos y los balances de la militante que ama, que recuerda, que se resiste al olvido. Las fotos que mira ya no son oficiales, son las de su álbum de familia, de sus hijas, de ella con Miguel. En el suelo un conejo y un oso de peluche, un carrito con juguetes, instalan un territorio que era 
M. Cecilia Herrera, C. Perduz Bedoya. Testimonio, subjetividad...

también infantil y le dan un tinte subjetivo a la trama (1:51). Esos son los activadores de la memoria con los que Castillo nos introduce en su mundo privado, al cual le da una connotación pública a través de una narrativa intimista en la que el yo muestra sus desplazamientos.

Más adelante distintas voces entran en juego a través de testimonios y entrevistas hechas a habitantes del barrio, a líderes sindicales, a jóvenes comprometidos, a mujeres militantes, de las cuales se desprenden tanto claves para dilucidar lo sucedido aquel 5 de octubre como para sopesar los sentimientos sobre la dictadura, las luchas de los sectores populares, así como el compromiso que frente a ellas tuvo el MIR como organización. De esta manera, aunque en sus distintos trabajos de memoria, Castillo es el centro de la narrativa, su relato se acompaña permanentemente de otras voces que marcan su propia historia como parte de una historia colectiva.

En este documental, la directora pondrá en escena sus múltiples identidades: “aquella de antigua militante, de mujer enamorada, de madre, de hija, de viuda, de exiliada. Esto parece explicar el cambio de interlocutores a lo largo de su documental, donde ella se dirige indistintamente a Camila (su hija), a Miguel, a su padre, afirmando de este modo la presencia de sus múltiples yo" (Ramírez, Op. Cit). Esta idea se refuerza en el libro de Castillo escrito con su madre Mónica Echeverría, en donde dice:

¿Quién regresa? ¿Cómo se llama? Tengo varios rostros, extrañas amistades, dos lenguas, al menos dos posturas. Me gusta decir que no pertenezco a ninguna parte, que siempre hablé francés sin acento. Estoy vestida de negro. Mis artimañas son múltiples, complejas, bien construidas. Poseo un don natural para renacer, cambiar, morir, rehacer hábitos. (...) No soy yo la que ha decidido hacer este trayecto en sentido inverso. (...) De todos mis rostros, el que más detesto: la sobreviviente (Castillo y Echeverría, 2002, p. 259, En: Ramírez, Ibid.).

Castillo alude también a las implicaciones del exilio en cuanto posibilidad de mirar el mundo fuera del referente de lo nacional, lo cual marca otro tipo de subjetividad que incorpora elementos cosmopolitas:

Soy chilena, de esas chilenas de la ruptura que produjo la dictadura (...) Como ciudadana del mundo lo miro todo con mis experiencias de chilena, porque el exilio me llevó a entender el mundo como un territorio que nos concierne a todas/os, me voy sintiendo ciudadana del mundo sin dejar de ser chilena, lo que sucede en el mundo me concierne y tengo el derecho y la necesidad de pensarlo, opinar, intervenir. Esta es una de las líneas de vida que pude sacar del dolor del exilio (Ibídem).

En dicha experiencia resalta su contacto con el movimiento feminista que le dará elementos para procesar los acontecimientos traumáticos desde una mirada de género: 
M. Cecilia Herrera, C. Perduz Bedoya. Testimonio, subjetividad...

Las que salimos exiladas, castigadas por nuestra propia posición o detrás del marido, conocimos el feminismo afuera, o sea contactamos con los instrumentos para entendernos y para integrar la fragmentación de nuestras existencias cuando ya no podíamos contactar con nuestros orígenes concretos, con muchos de esos fragmentos (...) Yo creo que el exilio fue más doloroso para nosotras, un sentimiento de retroceso hasta que nos encontramos con el feminismo. Fueron mujeres las que a mi me ayudaron a encontrar una nueva manera de recordar, de vivir y pensar que no la teníamos antes. En ese sentido, su experiencia se ligó a mi historia (Ibídem.).

Castillo empalma su pasado, con su presente y con el horizonte de futuro que sus vivencias y las maneras como han sido reelaboradas le trazan como sujeto político, mencionando como pasó de ser una sobreviviente a tener una existencia más íntegra en donde la percepción de la lucha política rebasa el marco nacional y el uso de las armas.

\section{El imaginario argentino y las grietas de la última dictadura}

Argentina, uno de los países, al igual que Chile y Uruguay, que alcanzó a finales del siglo XIX índices importantes de alfabetización, caracterizado por altas tazas de desarrollo industrial, había conseguido configurar una clase media numerosa hacia mediados del siglo XX, así como un nivel de vida aceptable en un margen amplio de la población, sufrió los estertores que acompañaron a toda América Latina, con la introducción de una dictadura cívico-militar entre 1976 y 1983 y, con ella, de las políticas que condujeron a la implantación del neoliberalismo en la región conllevando, dentro de numerosas consecuencias, a una especie de "emparejamiento por lo bajo" del nivel de vida de la población y del retroceso en las tazas de alfabetización.

Argentina portaba una tradición golpista a lo largo del siglo XX como expresión de algunos rasgos de su cultura política, marcados por cierto talante autoritario que se fue recrudeciendo al pasar de las décadas y condujo a su dictadura más reciente, aunque ésta tenga características que la diferencian de las anteriores, en especial en la generalización del uso indiscriminado de la violencia y la institucionalización del terrorismo de Estado. Así, en el período conocido como el Proceso (1976-1983), ya que los militares bautizaron la toma violenta del poder como Proceso de Reorganización Nacional, las distintas generaciones fueron afectadas, de una o de otra manera, por una amplia oleada de violencia política, cuyas consecuencias todavía marcan los destinos de los argentinos en los planos económico, político, social y cultural.

No obstante, Argentina ha sido uno de los países caracterizados por dinámicos procesos, no exentos de altibajos y conflictos, que ha buscado dar cuenta de ese pasado, a través de movimientos en 
M. Cecilia Herrera, C. Perduz Bedoya. Testimonio, subjetividad...

defensa de los derechos humanos, en los que las políticas de la memoria ocupan un lugar destacado y en donde, en su última fase, el juzgamiento a los responsables de la desaparición de 30.000 personas, y de un sinnúmero de niños/as apropiados/as por los victimarios, forman parte de la agenda pública. Dentro de este horizonte, los testimonios de distinta índole y en diversos formatos han tenido un despliegue importante obligando a la sociedad en su conjunto a revisar este período, y a evidenciar la importancia de reconfigurar las subjetividades individuales y colectivas desarticuladas por la violencia política y el terrorismo de Estado, fenómeno que ha dejado salir a la luz una multiplicidad de relatos en pugna y de memorias en conflicto en torno a las cuales todavía se avizora un trabajo de largo aliento en pro de los procesos de reconciliación.

\section{Pilar Calveiro: una sobreviviente que se mira a sí misma a través de los/as demás}

Pilar Calveiro fue secuestrada en el año de 1977, a la edad de 24 años, por un comando de la Aeronáutica en plena calle y llevada al centro clandestino de detención Mansión Seré en Ituzaingó, Provincia de Buenos Aires. Ella estuvo detenida-desaparecida en la comisaría de Castelar, la ex casa del Almirante Massera (en Panamericana y Thames) perteneciente al Servicio de Informaciones Navales, y en la Escuela Mecánica de la Armada (ESMA). En el año de 1978 se exilió en España y más tarde en México donde reside desde 1979. Pilar inició en la Universidad Nacional Autónoma de México (UNAM) su formación en ciencias políticas, llevando a cabo licenciatura (1986), maestría (1995) y doctorado (2001) en esta área. En 2014 recibió el Premio Konex - Diploma al Mérito en el campo de ensayos políticos y sociológicos.

Puede decirse que Calveiro ha ejercido su narrativa fundamentalmente en el campo académico, lugar desde el cual se ha dedicado a reflexionar sobre la violencia política de los años 70 y la experiencia argentina, caracterizada por los campos de concentración-exterminio en donde ella misma estuvo por el lapso de un año y medio. Calveiro es alguien a quien no le gusta hablar en sus textos de manera directa sobre su experiencia, aunque haya dado numerosas entrevistas en las que alude a ella; más bien procura acopiar testimonios en los que a modo de espejo sus vivencias son narradas por quienes compartieron una experiencia similar. Ella habla de sí exponiendo a los/as demás y se dedica a fundamentar teóricamente sus reflexiones sobre los acontecimientos traumáticos que marcaron este período y causaron daños irreparables desde el punto de vista de lo social, pero también de lo individual: ella misma perdió a su compañero Horacio Domingo Campiglia, en 1980, quien fue detenido en Brasil y trasladado a Argentina para luego "desaparecerlo" como una víctima más del plan Cóndor, al tiempo que, como ya dijimos, estuvo detenida-desaparecida y posteriormente se tuvo que marchar al exilio. 
M. Cecilia Herrera, C. Perduz Bedoya. Testimonio, subjetividad...

En el año de 1988 Pilar publicó, con base en su tesis doctoral, el libro Poder y desaparición, reeditado en 2004 (traducido al francés, al italiano y al portugués), en el cual proporciona un análisis profundo y descarnado sobre el funcionamiento de los campos como dispositivos de disciplinamiento y subjetivación, haciendo uso de testimonios y apoyada en un referencial que bebe de Foucault y de Arendt para sus análisis. La autora no vacila en mostrar las intencionalidades del Proceso de recomponer el orden social de manera radical, en donde el dispositivo de los campos marca el derrotero del poder desplegado en distintas esferas sociales.

En su libro Calveiro retoma el debate sobre el análisis del Estado y de la política en torno a las tensiones entre fuerza y forma, para afirmar que al considerar la política más en términos de fuerza y hacer uso de la violencia, los jóvenes adscritos a organizaciones político-militares en el período, no introdujeron ninguna novedad en el contexto nacional e internacional. Según sus análisis la violencia ya estaba enraizada en la política argentina desde los años 30 del siglo XX, señalando los distintos hechos violentos que marcaron el entorno en el que creció esta generación (dentro de los cuales menciona la proscripción del peronismo entre 1955 y 1973, que representaba la mayoría electoral compuesta por los sectores más desposeídos de la población). "Por eso la guerrilla consideraba que respondía a una violencia ya instalada de antemano en la sociedad" (Op. Cit., p. 8). A lo cual agrega: "Al inicio de la década del 70, muchas voces, incluidas las de los políticos, intelectuales, artistas, se levantaban en reivindicación de la violencia dentro y fuera de Argentina" (ibid).

A través de la descripción y análisis de los campos con base en la mirada de los testigos, de los cuales ella es una, Pilar muestra como la máquina concentracionaria buscó moldear y reformatear los sujetos teniendo como base la tortura, la pérdida de la identidad y el universo tabicado que configura sujetos fragmentados, con base en una lógica binaria de amigo/enemigo, adentro/afuera, que permea al conjunto de la sociedad. No obstante, la autora también se cuida de mostrar las fisuras de este universo concentracionario y señala los modos como los sujetos encontraron puntos de fuga y de resistencia frente al mismo. Así, aunque el objetivo de la tortura era el de "lograr la producción de un nuevo sujeto, completamente sumiso a los designios del campo", la sumisión nunca se puede considerar como total:

El campo intentó arrasar la personalidad y toda forma de resistencia a través de la tortura sistemática, ilimitada, irrestricta, produciendo dolor, terror, parálisis, pero no necesariamente lo logró. No hay técnicas infalibles, y la tortura tampoco lo fue. A pesar de los interrogadores, frente a ella había hombres, no masilla moldeable. Seres humanos que reaccionaron de las más diversas maneras (p. 44). 
La idea de un universo binario, reforzado por las políticas de seguridad nacional propendidas por Estados Unidos y la lógica de la Guerra Fría, llevó a situar a los disidentes como sujetos que se contraponían a lo que se consideraba el sujeto nacional argentino (Giordano, 2005, p. 85). Bajo la lógica de amigo/enemigo toda oposición al régimen fue elaborada desde la idea de un Otro ajeno, extraño, demonizado, cuyos puntos de vista no tenían ninguna legitimidad y sin derecho al respeto de su vida; un Otro al cual se denominó como subversivo cuyos límites y alcances invadieron buena parte de los intersticios societales. De este modo bajo la figura del sujeto subversivo se obturaba cualquier expresión diferente a lo que se concebía como parte del proceso de reorganización nacional, en el cual se descartó a los que se consideraban como malos dentro del universo binario:

No quedó el menor espacio para el disenso; cualquiera de sus formas ameritaba la calificación de subversivo con todas las secuelas que ya se explicó. Se desconoció la identidad de la sociedad o las identidades constitutivas, pretendiendo amoldar un país de grandes matices al esquema occidental, cristiano, burocrático y mediocre de los administradores militares (p.96).

Si bien la figura del subversivo, como el sujeto Otro que debía ser anulado por el sistema por considerarlo no funcional (ajeno), abarcó un amplio espectro, Calveiro es tajante en afirmar que buena parte de los detenidos-desaparecidos tenían algún tipo de militancia política, social o sindical, y muestra la importancia de hacer explícita dicha militancia en la recuperación de la memoria sobre ese período, así como las características de los sujetos que fueron aniquilados y los proyectos e idearios de los que eran portadores (p. 102).

A lo largo de sus diferentes textos y de las entrevistas concedidas Calveiro es crítica sobre el accionar de los grupos armados revolucionarios, incluido el de Montoneros en el cual militaba cuando fue detenida, al indicar como la creciente militarización de estas organizaciones puso en segundo plano la acción política y el contacto con los sectores populares a los cuales se decía representar, al tiempo que no les permitió sopesar sus condiciones desventajosas para enfrentar militarmente al régimen dictatorial contribuyendo, con sus acciones, al escalonamiento de la violencia, tema que aborda con amplitud en su texto Política y/o violencia: Una aproximación a los años 70 (2005), en el cual interpela a sus compañeros a someter a crítica sus prácticas y asumir las responsabilidades que les caben para aportar al esclarecimiento del pasado de violencia política. En entrevista a Pikielny (2012) condensa sus argumentaciones indicando, entre otras, como el binomio política/violencia está presente en la sociedad con sus distintas modulaciones y debe ser enfrentado en los análisis políticos:

La heroización de los setenta es contraproducente y obtura la discusión porque no permite hacer el análisis crítico de esa época, y pensar en la responsabilidad que les cupo a los distintos actores políticos. Yo no creo en la política como forma de exclusión de la violencia. Creo más bien que en 
M. Cecilia Herrera, C. Perduz Bedoya. Testimonio, subjetividad...

la política siempre hay un núcleo violento y lo que hay que ver es qué lugar ocupa este núcleo violento, cuáles son las formas de la violencia, y cómo operan en relación con el poder instituido y con las resistencias a este poder (...) En el contexto de democracias participativas esto requiere una formulación. No puede pasarse al desconocimiento de esta relación entre política y violencia como si esto hubiera desaparecido y como si en las democracias no existiera esta relación (Calveiro en Pikielny, p. 3).

Es importante resaltar la significación que Calveiro le da a testimoniar sobre su experiencia en los campos como parte de la necesidad que tenían todos los que estuvieron en los lugares en los que ella estuvo. No obstante, para ella el testimonio, su testimonio, debía estar acompañado de una explicación inscrita en una narrativa de carácter político que le diera mayor inteligibilidad:

Había que contar tratando de explicar. Siempre pensé que era una historia política, que entrañaba un montón de dramas personales, pero que era esencialmente política y había que contarla desde la política, hablar del proyecto militar y de su confrontación por parte de las organizaciones armadas (Calveiro en Gelman, 1998).

Al preguntársele sobre lo qué significa para ella la palabra militancia en el contexto actual afirma que:

La militancia es una apuesta de vida por un proyecto político. Los proyectos políticos de hoy son diferentes de los que existían en los setenta y la militancia tiene otras características. Me parece que hay una parte importante de la sociedad, y en particular gente joven, que vuelve a hacer una apuesta política y en ese sentido vuelve a pensar a la política como parte de su apuesta de vida. Ahora bien, las características de la militancia cambian si uno está cobijado por el gobierno, si uno está en la oposición o si uno está en la clandestinidad. Son circunstancias muy distintas de la militancia que exigen también compromisos diferentes (Pikielny, Op.Cï.).

\section{De la Violencia con nombre propio a la violencia como fenómeno persistente en Colombia}

A diferencia de Argentina, las dictaduras en la historia reciente de Colombia no han sido ni numerosas ni extensas, de forma tal que a la democracia colombiana se le ha llegado a considerar como la más antigua y estable del continente, valga decir que bajo largos períodos de estado de sitio. Sólo en 1953 el General Gustavo Rojas Pinilla se tomó el poder por la vía del golpe de Estado y se consagró como el único dictador del país. Para esa fecha Colombia se hallaba sumida en una profunda violencia que mereció nombre propio (La Violencia) y tuvo como actores a simpatizantes de las dos fuerzas políticas tradicionales: el Partido Liberal y el Partido Conservador, en todo el territorio, incluso de los 
M. Cecilia Herrera, C. Perduz Bedoya. Testimonio, subjetividad...

más recónditos campos del país. Este gobierno se prolongó hasta 1957 cuando Rojas Pinilla comenzó a tomar vuelo propio y su figura a imponerse en tono caudillesco; de ahí, ante diferentes presiones cedió el poder a una Junta Militar y partió al exilio, para que en 1958 los dos grandes actores que ostentaban el bipolio de la esfera política, liberales y conservadores, presentaran el acuerdo del Frente Nacional.

Para las elecciones de 1970 Rojas Pinilla se presentó como candidato presidencial por la Anapo (Alianza Nacional Popular, partido que había fundado a su regreso a Colombia), una coalición de fuerzas liberales y conservadoras disidentes y algunos sectores de la izquierda. El 19 de abril, luego de que Rojas fuera prácticamente declarado ganador por los medios de comunicación, vinieron eventos dudosos con los cuales se otorgó el triunfo electoral a Misael Pastrana Borrero, el candidato conservador. Es a este hecho que se le atribuye la conformación del M-19 (Movimiento 19 de abril), por parte del ala socialista de la derrotada coalición, como brazo armado de la Anapo.

El M-19 actuó como movimiento guerrillero durante dieciséis años (1974-1990) sufriendo fuertes represiones en el periodo de 1978 a 1982 bajo el gobierno de Julio César Turbay Ayala, quien impuso un Estatuto de Seguridad, con el amparo de la figura del Estado de Sitio. Sería una época de abusos militares en un país donde, se suponía, reinaba la democracia y que estaría en consonancia con los lineamientos que guiaban las actuaciones de las dictadura del Cono Sur en donde se configuraba el sujeto opositor político, con cualquiera de sus matices, como subversivo y, por lo tanto, indeseable.

Luego de algunos intentos fallidos por consolidar la paz durante el gobierno de Belisario Betancur (1982-1986), el M-19 y otras organizaciones armadas lograron este propósito en el año 1990 bajo el gobierno de Virgilio Barco. No obstante la voluntad de paz de los ex-guerrilleros pertenecientes a las organizaciones firmantes, representada en la entrega de las armas y la reintegración a la vida civil, los desmovilizados fueron objeto de persecuciones y asesinatos. Algunos de los sobrevivientes debieron exiliarse o continuar su vida en el país casi que en condición de clandestinidad; algunos de los excombatientes decidieron, incluso, excluirse de las listas de desmovilización por temor a represalias.

\section{Los devenires del ser mujer en Razones de vida}

Vera Grabe, militante del M-19 publicó en el año 2000 una autobiografía bajo el título Razones de vida, la cual fue reeditada en 2011 con una modificación en el título: Del silencio de mi cello o razones de vida y con una nueva editorial: Obserpaz, del Observatorio para la Paz, institución en la cual ella ha trabajado durante los últimos años. Razones de vida se teje a partir del diálogo que la autora pretende entablar con su hija, Juanita, a quien trata explicar las causas que motivaron sus decisiones y de 
M. Cecilia Herrera, C. Perduz Bedoya. Testimonio, subjetividad...

entregarle el legado de su historia personal la cual abarca, en buena parte, los años de la historia reciente de Colombia; en ese sentido, es también un diálogo con el país, hacia el cual procura un acto de memoria pactado en su narrativa.

Razones de vida se compone de doce apartados a través de los cuales la autora se desplaza por diferentes momentos de su vida familiar, personal y militante, en un intento por recorrer de forma cronológica su propia historia y la del M-19. En su narrativa es posible observar tres grandes momentos: el antes, el durante y el después del Eme -también podría decirse, de la opción por las armas-; estos son, a grosso modo, los puntos de inflexión a partir de los cuales se pueden rastrear las reconfiguraciones subjetivas de la autora. Con su mirada antropológica y su innegable formación política reconstruye el contexto de cada una de las situaciones a las que se acerca y, además, ausculta sus motivaciones en la historia, en el pasado suyo, el de sus padres, el del país, tanto por una búsqueda personal como por ofrecer un marco de inteligibilidad a los acontecimientos que signaron los rumbos del país en esas décadas.

Abonos para la militancia (El Antes). En el primero de los apartados, Raíces y pinitos, Vera se aproxima a las circunstancias familiares, personales y del contexto histórico que le llevaron a ciertas búsquedas y, como parte de ellas, a la militancia en el M-19. Dicho de otro modo, expresa una reflexión en torno a situaciones que de manera consciente o no configuraban su subjetividad abonando terreno a la opción de la militancia: el legado de sus padres, el contexto histórico del país, los sucesos que daban viraje al mundo a lo largo de estas décadas.

Sus padres llegaron a Colombia luego de terminada la Segunda Guerra Mundial, en busca de un lugar para comenzar de nuevo y poder brindar un hogar a los hijos (las hijas, en realidad) que estaban por venir. Su padre había sido víctima de persecuciones, llevado a dejar su trabajo como ebanista y obligado a trabajos forzados por las fuerzas nazistas. La carga histórica no vendría solamente del pasado de asedio de sus padres. En la búsqueda de un lugar que marcara un empezar de ceros, la llegada a Colombia les ofrecería la posibilidad de que la violencia estuviera presente, tal vez relativamente distante, pues, mientras se mantuvieran al margen, incluso de la opinión, podrían vivir en relativa paz. No obstante, el país se encontraría en años de fuertes confrontaciones y del recrudecimiento de la violencia (Grabe, 2000, p. 17).

Los cambios por los que estaba atravesando el mundo también serían determinantes para las juventudes en Colombia en lo referente a sus búsquedas y apuestas vitales. Para los adolescentes de los años 70 una nueva época surgía. El mundo acudía a la revolución. No solo el poder político era la fuente de fuertes cuestionamientos, sino que los cambios llegarían a todas las esferas de la vida. Sería un 
M. Cecilia Herrera, C. Perduz Bedoya. Testimonio, subjetividad...

momento de discusión de los cánones tradicionales y de reconfiguración del ser mujer -con opciones diferentes en cuanto a la fertilidad, el amor, la belleza y el rol social-, de la juventud, de la iglesia y del Estado (p. 30-31).

"Cuando el yo se volvió nosotros" (El Durante). Esa es la manera como Vera decide titular el apartado en el cual narra su integración al M-19 en 1974. Allí expone los principios que empezaban a regir en la organización, sus posturas en relación con el uso de las armas, respecto a lo cual afirma: "El arma era portadora y estaba al servicio de un ideal de país, de sociedad, de una ética (p. 59)”. Escrita desde la distancia que ofrecen tanto el tiempo como las circunstancias la mirada hacia el paso por el Eme se constituye en un ir y venir de cuestionamientos acerca de los límites de la colectividad y del individuo; así, al tiempo que se observa en Vera la alegría de sentirse parte de un proyecto en el cual se expresaban sus deseos de cambio se vislumbra la inquietud por sí misma, por configurarse como un ser independiente de la organización (p. 90).

Vera fue apresada el 26 de octubre de 1979, cuando estaba en vigencia el Estado de Sitio, luego de que la organización robara 5000 armas al Ejército Nacional en Bogotá. Es en este punto donde se encuentra una de las inflexiones subjetivas en el relato de Vera: la tortura, desde cuya narración se hace énfasis en la reafirmación del nosotros, como expresión de triunfo sobre el enemigo, en el marco de una experiencia a la cual el sujeto se enfrenta en soledad. En contraste con el resto del relato, el pasaje de la tortura rehúye a ordenaciones cronológicas, pues, la autora hace énfasis en la pérdida de la noción del tiempo y el espacio (p. 99-101).

Con la mayoría de sus líderes en las cárceles, el M-19 puso de presente la existencia de presos políticos en Colombia a través de un hecho ampliamente recordado que los catapultaría y marcaría los derroteros de la lucha política y militar como coexistentes: la toma de la embajada de República Dominicana. Si bien no se logró ni la libertad ni la amnistía de los presos políticos lograría visibilizar al Eme como una organización que buscaba "la concientización por encima de la violencia" (p. 118). Se pondría sobre la mesa, también, "el desconocimiento de los derechos humanos al interior de nuestro territorio y el uso de tratos crueles y degradantes que lesionaban la dignidad humana" (p. 118). Asimismo, con este hecho "Por primera vez en la historia moderna de Colombia, una organización guerrillera levantaba la bandera de la paz, y de la negociación como salida al conflicto, y fue bien recibida” (p. 119). En adelante se enfrentarían al binarismo entre guerra y paz: "Lo fundamental era acortar los tiempos de la guerra, con la propuesta en una mano, y la decisión de construir un ejército en la otra" (p. 166). Así, al tiempo que se intentaban acercamientos con el gobierno con propuestas de diálogo se procuraba el fortalecimiento militar de la organización (p. 181). 
M. Cecilia Herrera, C. Perduz Bedoya. Testimonio, subjetividad...

En 1984 el gobierno de Belisario Betancur inició un proceso de diálogos que además del entusiasmo inicial o el desconcierto para algunos de los miembros de la organización dejaría como resultado un clima de desconfianzas mutuas. Como resultado de ataques militares en medio de treguas firmadas, el M-19 se sentiría traicionado en sus intenciones. Es en este contexto que surge en 1985 el plan de la toma del Palacio de Justicia con el propósito de llevar a cabo un juicio público al entonces presidente, Belisario Betancur, por el incumplimiento de los acuerdos. La toma sería una forma de hablarle al Estado desde el reconocimiento de sus instituciones, en este caso, la Corte Suprema de Justicia. La toma del Palacio se configuraría como uno de los acontecimientos de mayor recordación en la historia reciente de Colombia, cuyas heridas aún no logran ser sanadas, un acontecimiento emblemático por el cual militares y guerrilleros serían fuertemente cuestionados y que marcaría importantes rupturas en diferentes sentidos: "La tragedia del Palacio y otros hechos [...] nos fueron mostrando el primer límite de la guerra como opción de transformación. Límites de la guerra y nuevas fronteras de la paz” (p. 256).

La reconciliación por todos los frentes (El Después). La decisión de la paz no afectó a todas las excombatientes por igual. Para algunas sería sinónimo de contradicción, de abandono, de pérdida de identidad colectiva, de desgarramiento. Para Vera ha sido fundamental la continuidad del trabajo por la construcción de la paz. Además de su vida política como senadora (1990-1994) y como consejera para los Derechos Humanos en la Embajada de Colombia en España (1994-1997), de su aspiración a la vicepresidencia de la República (2002), y de su vida como académica, Vera ha debido pasar por tales procesos de reconfiguración: "para mí fue clave entender que a través de mi propia vida hubo muchas maneras de asumir la paz” (p. 215).

La reflexión de la mujer como género es un asunto que atraviesa la obra de Vera, aunque la consciencia de tal se da a partir de la última etapa del Eme como organización armada. En Razones de vida se muestra como mujer que ama, vive, siente, experimenta y se busca a sí misma en cada uno de sus actos. En todas y cada una de sus etapas en la militancia Vera Grabe se vio retada por los hombres, debió esforzarse el doble para lograr ser escuchada y negarse a las pretensiones de las partes amigas que pretendían a la mujer como transacción. Reconoce las posibilidades que le dio el Eme pero también las limitaciones y contradicciones... su cuerpo, como el de muchas colombianas y latinoamericanas fue también el arma de guerra utilizada por los torturadores. Asimismo, Vera reconoce la fuerza femenina en las luchas sociales y en la preservación de la memoria, al evocar su papel en el momento de mayores detenciones en la organización:

Las mujeres se erigieron en pilar de la defensa de los derechos humanos y la libertad de los presos políticos. Como sucede siempre: las madres de la Plaza de Mayo, las mujeres de negro, las madres 
M. Cecilia Herrera, C. Perduz Bedoya. Testimonio, subjetividad...

chechenas que se enfrentaban a los tanques para ganar la guerra fratricida. Madres, hermanas, abuelas, tías, sobrinas, hijas, amigas, eran el motor de los comités y asociaciones que persistían haciendo denuncias, encuentros, y cabildeo entre los políticos por una amnistía general (p. 123).

A las mujeres excombatientes no las abandona el prejuicio de guerreras, se les concibe como mujeres de armas tomar (literalmente) y, en ese sentido, se entenderá la prevención que recae sobre ellas en términos de las sociabilidades, en un momento histórico en el cual la vía de las armas perdió legitimidad. Desde allí Vera intenta comprender su transcurrir en el Eme como una búsqueda de paz; así lo reivindica en este párrafo en el cual le habla a su hija:

La tuya es una generación de paz. La mía también lo fue, aunque de otra manera. La paz tiene tantas caras como épocas. También entonces la paz y la libertad estuvieron presentes. Movilizaron por igual a hippies y guerrilleros. Unos dijeron no a la guerra. Los otros abrazaron las armas contra las formas ancestrales de violencia. Todos lo hicieron como una gran entrega de amor. Ese amor todos los ejercieron en cada acto cotidiano. Otros en la política y la lucha por una sociedad justa. Paz y libertad también se vivieron en la música, en el amor. Todos reivindicaban el derecho a la felicidad. Para unos era vivirla; para otros una utopía por alcanzar, asi no fuera para símismos (cursiva original del texto, p. 30).

\section{Conclusiones}

Como hemos intentado mostrar, los acontecimientos de la historia reciente han marcado en Latinoamérica expresiones de la violencia política que han sido determinantes en las subjetividades de quienes fueron protagonistas, de diferentes formas, en el curso de los conflictos. Nos referimos, de manera particular, a los sujetos que tuvieron una participación activa desde la oposición a los regímenes dictatoriales, en el caso de Argentina y Chile, y a los gobiernos de turno en el marco de la democracia restringida en otros países como Colombia; gobiernos desde los cuales se pretendió, además de la creación de condiciones para el establecimiento de un proyecto político-económico cercano a los intereses norteamericanos, la obtención del control social, político e ideológico a través de la represión de cualquier intento de antagonismo; poniendo, así, a los movimientos sociales y a los grupos políticos de oposición, algunos de ellos alzados en armas, en la mira de las políticas represivas.

Las organizaciones de oposición contaron en sus filas con la militancia de mujeres que desafiaron las normas establecidas en torno a los roles que éstas debían desempeñar en la sociedad, marcados por la dominación masculina y por la delimitación a los espacios domésticos y privados. Muchas de ellas le apostaron a un proyecto revolucionario que marcó de manera definitiva la configuración de sus 
subjetividades y sus actuaciones en la esfera de lo público y sufrieron también los rigores de la represión política y del quiebre de muchos de sus sueños en el plano personal y colectivo.

En esta dirección, el presente artículo nos permitió un acercamiento a las percepciones y sensibilidades de algunas mujeres que fueron protagonistas de este período, dejándonos entrever, desde diferentes matrices discursivas desplegadas a través del trabajo literario, cinematográfico, académico, político y pedagógico, las sinuosidades de los procesos de subjetivación y las complejas articulaciones entre lo individual y lo social. 
M. Cecilia Herrera, C. Perduz Bedoya. Testimonio, subjetividad...

\section{Bibliografía citada}

Arce, Luz (1993). El infierno. Santiago: Planeta.

Bedregal, Ximena. Entrevista con Carmen Castillo: La dictadura, gran máquina del olvido, convirtió a Chile en país de la amnesia general (Abril 5, 1999).

Calveiro, Pilar (1998). Poder y desaparición. Los campos de concentración en Argentina. Buenos Aires: Colihue.

Calveiro, Pilar (2005). Política y/o violencia. Una aproximación a la guerrilla de los años 70. Buenos Aires: Norma.

Castillo, Carmen [1992/1999 (1980)]. Un día de octubre en Santiago/Un jour d'octobre à Santiago. París: Éditions Bernard Barrault/ Santiago: LOM Ediciones.

Castillo, Carmen (1993). La Flaca Alejandra. Chile/Francia/Reino Unido: Ina, France 3, Channel 4.

Castillo, Carmen (2002). Calle Santa Fe. Francia/Chile: Parox Producciones S.A., Les Films d'Ici, Les Films de la Pässerelle, Institut National de l'Audiovisuel-INA, Love Streams Agnès b Productions.

Castillo, Carmen y Echeverría, Mónica (2002). Santiago-Paris: El Vuelo de la Memoria. Santiago: LOM.

García, Victoria. “Diez problemas para el testimonialista latinoamericano: los años '60-'70 y los géneros de una literatura propia del continente". Castilla. Estudios de Literatura 4 (2013): 368-405.

Gelman, Juan. "Pilar Calveiro describe la vida-muerte de los campos de concentración: 'Una está en otra dimensión" Páginal2 (1998).

Giordano, María Graciela (2005). Más allá del trauma colectivo: represión y exilio en la narrativa de mujeres y el cine argentino (tesis doctoral). Montreal: MeGill University.

Girard, René (1982). La violencia y lo sagrado. Barcelona: Anagrama.

Grabe, Vera (2011). Del silencio de micello o razones de vida. Bogotá: Obserpaz.

Merino, Marcia (1994). Miverdad. Santiago: AGT.

Ochando Aymerich, Carmen (1998). La memoria en el espejo: aproximación a la escritura testimonial. Barcelona: Anthropos. 
Peris Blanes, Jaume (2008). Historia del testimonio chileno. De las estrategias de denuncia a las políticas de memoria. Valencia: Anejos de Quaderns de Filologia.

Pikielny, Astrid. "Pilar Calveiro: 'La visión heroica de los años 70 es contraproducente porque obtura la discusión"”. La Nación (2012).

Ramírez, Elizabeth. "Memoria y desobediencia. Una aproximación a los documentales de Carmen Castillo". La fuga (2010).

Ricoeur, Paul (1998). Poderyviolencia.

Ricoeur, Paul (2002). "Ética y moral”. Gómez, Carlos (ed.) Doce textos fundamentales de la ética del siglo XX. Madrid: Alianza Editorial: 241-255.

Ricoeur, Paul (2009). Educación y políica. De la historia personal a la comunión de libertades. Buenos Aires: Prometeo.

Robledo, Ángela Inés (2012). Razones de vida otra vez o Del silencio de mi cello que es punto de llegada para iniciar otro ciclo.

Yúdice, George (2003). "De la guerra civil a la guerra cultural. Testimonio, posmodernidad y el debate sobre la autenticidad". Castro-Klaren, Sara (eda.) Narrativa femenina en América Latina. Prácticas y perspectivas teóricas. Vol. 24. Madrid: Iberoamérica: 111-142.

Zabaleta, Martha. "Acerca de la memoria: voces revolucionarias del Sur" Topia (2006). 